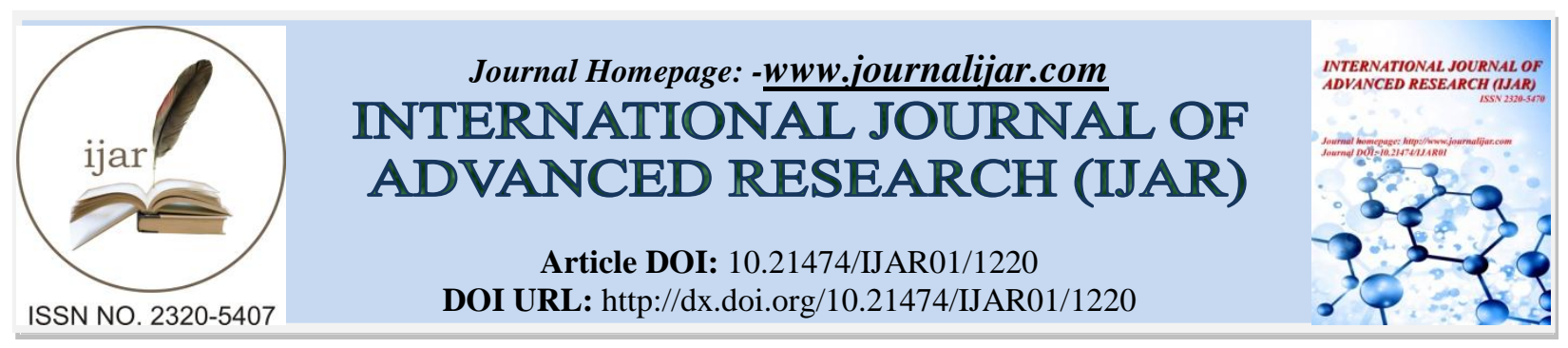

RESEARCH ARTICLE

\title{
CARBON NANOTUBE DOPED HYDROXYAPATITE: A STUDY FOR PROPANOL DETECTION.
}

\author{
S. R. Anjum and *R. S. Khairnar.
}

Schoolof Physical Sciences, Swami Ramanand Teerth Marathwada University Nanded, India.

\section{Manuscript Info}

Manuscript History

Received: 12 June 2016

Final Accepted: 22 July 2016

Published: August 2016

Key words:-

Hydroxyapatite,

Carbon nanotubes,

Gas sensor,

\section{Abstract}

$\left(\mathrm{C}_{3} \mathrm{H}_{7} \mathrm{OH}\right)$ sensing at its lower concentration by means of nano ceramic composite. It involves the synthesis of Hydroxyapatite (HAp) and preparation of nano composite material by doping various weight concentrations of carbon nanotubes (CNT) in HAp. Moreover, it also involves characterization of their nanostructure and analysis of their gas sensing behavior after interacting with organic vapors like Propanol. The surface morphology of the synthesized material and prepared composites is characterized by X-Ray Diffraction (XRD) and Branauer-Emmett-Teller (BET) analysis. The gas sensing parameters such as operating temperature, response / recovery time, and maximum detection limit are studied. The influence of doping material in HAp matrix for propanol sensing is studied. Carbon nanotubes (CNT) doped HAp materials show higher sensitivity than pure HAp, The thick films of $0.2 \mathrm{wt} \%$ CNT doped HAp gives much efficient sensor substrate for the detection of $100 \mathrm{ppm}$ Propanol at a temperature of $60^{\circ} \mathrm{C}$.

The study deals with the

investigation of Propanol

Copy Right, IJAR, 2016, All rights reserved.

\section{Introduction:-}

Calcium Hydroxyapatite $\left(\mathrm{Ca}_{10}\left(\mathrm{PO}_{4}\right)_{6}(\mathrm{OH})_{2}\right)$ is a kind of nano ceramic inorganic material. It has a wide range of applications in medical as well as the non-medical field. The medical applications involves osteointegration process, replacements of bone fragments, repairing of bone defects, suppressed inflammation process and potential use for heal bone fractions (P. Chavan et al., 2009, H. Ivankovic et al., 2010, J. Klinkaewnarong et al., 2010, H. Zhao et al., 2009). Whereas for non-medical applications it is used in drug delivery system(Betsiou M et al., 2007), chromatography (Comming Li et al., 2009), cation exchange (Cawthray F. et al., 2015), catalysis process (Mohamed Zahouily et al., 2005), waste water treatment(Narwade V. N. et al. 2014), and as gas sensing substrate(R. U. Mene et al., 2014, R. U. Mene et al., 2010, Li Huixia et al., 2015, R. U. Mene et al., 2011, R. U. Mene et al., 2011). It is selected as a candidate for gas sensing application because of the properties of non-toxicity, porous hexagonal structure, significant ionic conductivity, adsorption capacity' large surface area, and high thermal stability. In our previous publications we utilized HAp surface as sensing substrate for the detection of gases like $\mathrm{CO}$ and $\mathrm{CO}_{2}(\mathrm{R}$. U. Mene et al., 2010) and organic vapours like methanol, ethanol (Rajendra S. Khairnar et al., 2015), and ammonia (Rajendra S. Khairnar et al., 2015). Also the surface of HAp is modified by swift heavy ion irradiation (R. U. Mene et al., 2011) and by doping different nanomaterials like cobalt, Fe, graphite, carbon nanotubes (CNT), reduced graphene oxide, titanium oxide etc. in order to achieve an efficient surface for gas sensing application. In present work we utilised carbon nanotube doped Hydroxyapatite sensing substrate for the detection of propanol. The surface

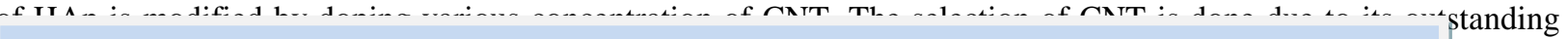

Corresponding Author:- R. S. Khairnar.

Address : -Schoolof Physical Sciences, Swami Ramanand Teerth Marathwada University Nanded, 
characteristics features like high aspect ratio, large adsorption capacity, and large change in electrical properties in presence of different gases at low operating temperature (B. S. Dasari et al., 2015, Joseph C. Obirai et al., 2008, A. Ghasemi et al., 2012, Y. Du et al., 2015). The major goal of the work is to develop an efficient sensing substrate for the detection of propanol vapors at low temperature or at room temperature. The report involves a comparative study of two different sensing substrates, viz., pure HAp and CNT doped HAp, in terms of their gas sensing characteristics such as operating temperature, response/ recovery time, gas uptake limit etc.

\section{Material and Methods:-}

The nano crystalline HAp powder $(\mathrm{Ca} / \mathrm{P}$ molar ratio $1: 6)$ is prepared by a simple wet chemical precipitation method as described earlier (R. U. Mene et al., 2010). CNT in different weight concentrations (0.05, 0.1, 0.2, 0.5, 0.6, $0.7 \mathrm{wt}$ $\%)$ is dispersed in HAp having a fixed weight concentration. The sensing characteristics of the substrate are studied by preparing thick films of the material. Screen printing technique as explained previously is adopted for this purpose (Rajendra S. Khairnar et al., 2014). The crystal structure of the undoped and doped HAp is characterized on

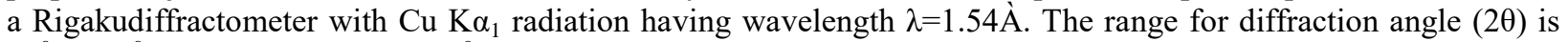
$20^{0}$ to $60^{\circ}$ with the scan rate of $2^{0} / \mathrm{min}$. The crystal size is calculated using Debye Scherer's formula. The specific surface area of the material is characterized by Branauer- Emmett- Teller (BET) analysis. The Barrett-JoynerHalenda $(\mathrm{BJH})$ is employed to determine pore size and total pore volume of the material.

\section{Result and Discussion:-}

The X-ray diffraction profile for pure and doped HAp depicted in Figure 1 confirms its hexagonal phase structure as per standard hexagonal HAp peaks reported in JCPDS card (00-009-0432). The crystal phase of HAp is found to be stable even after the addition of CNT in variable concentrations. The crystallite size, calculated using Debye Scherer's formula for pure and CNT doped HAp, is ranged between $25-40 \mathrm{~nm}$. The nitrogen adsorption desorption isotherm for the doped and undoped material is displayed in Figure 2(A). The observed isotherm is identified as type III isotherm showing a weak interaction between adsorbent and adsorbate. Figure 2 (B) represents the BJH pore size distribution curve for the doped and undoped material. It suggests the mesoporous nature of the material. The detailed information about the BET analysis is shown in table 1.

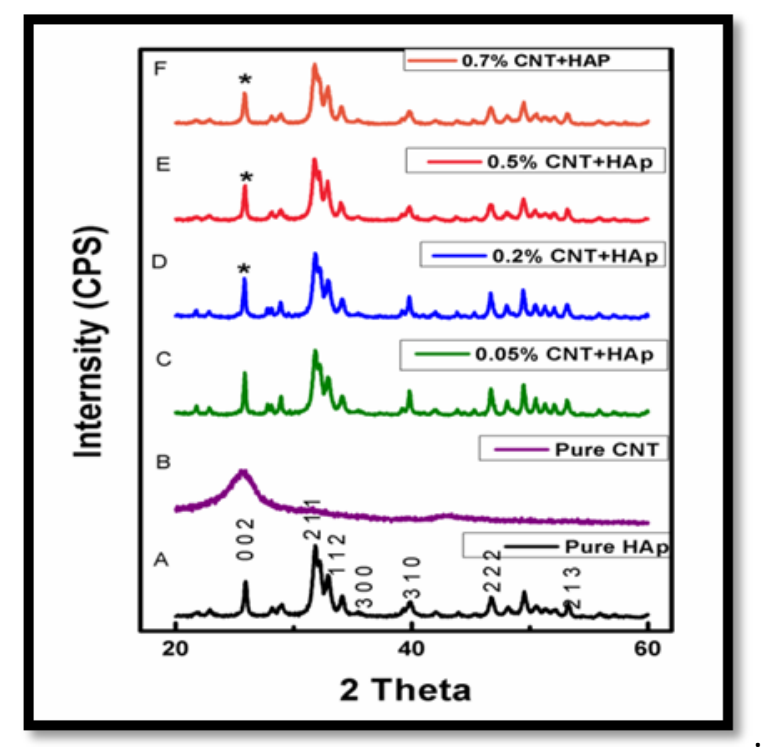

Figure 1 XRD profile for (A) undoped HAp, ,(B) undoped CNT, (C) 0.05 CNT doped HAp, (D)0.2 CNT doped HAp, (E)0.5 CNT doped HAp,(F) 0.7CNT doped HAp. 


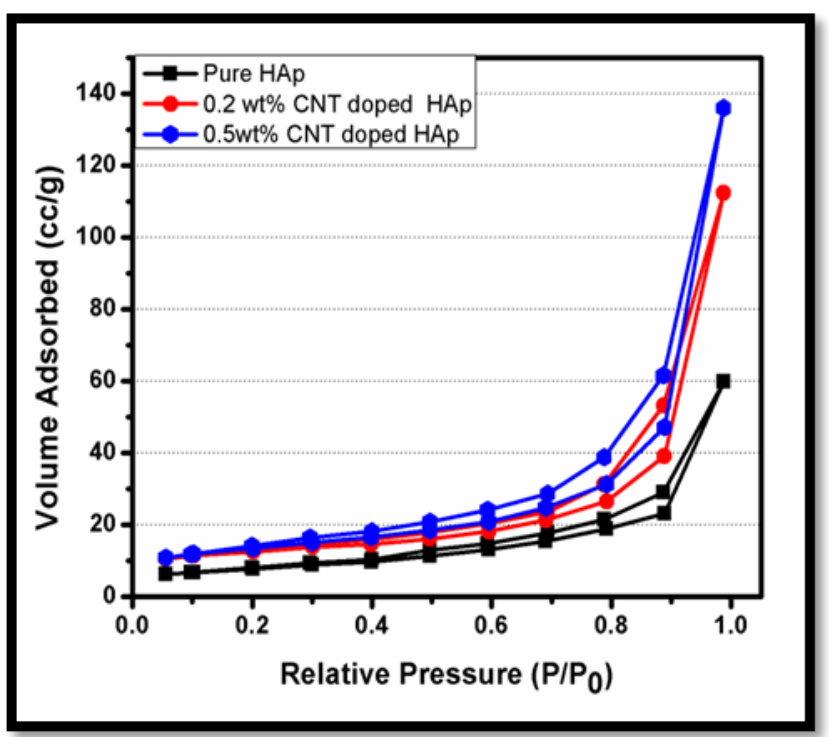

Figure 2(A) $\mathrm{N}_{2}$ adsorption/desorption isotherms for pure HAp, 0.2wt\% CNT doped HAp and 0.5wt\% CNT doped HAp
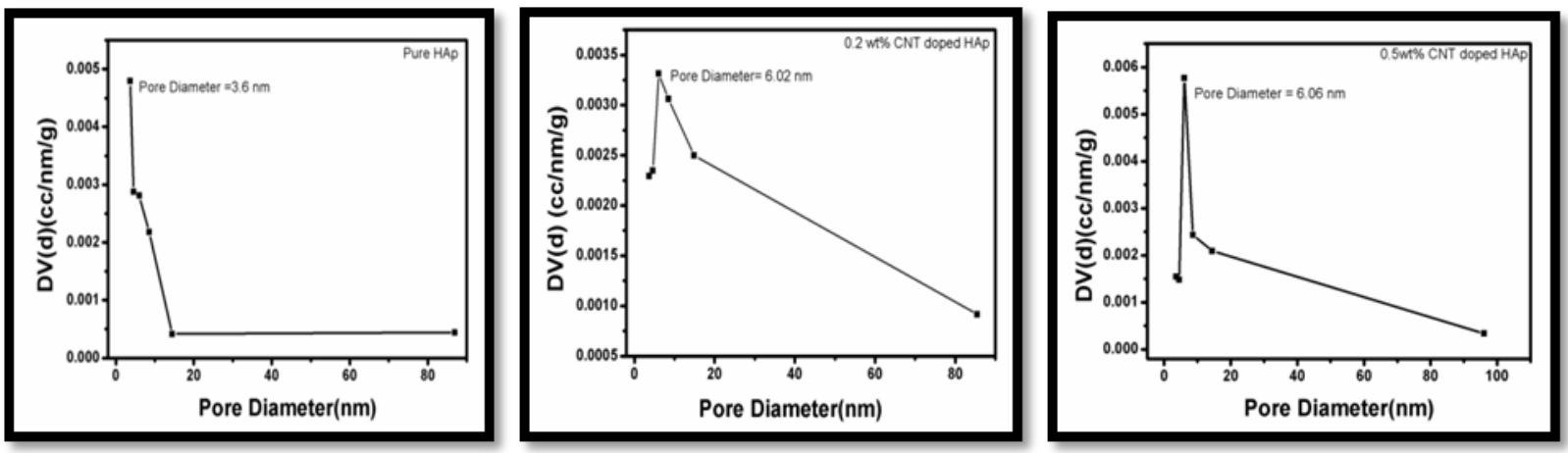

Figure 2(B) BJH pore size distribution curve for pure HAp, 0.2wt $\%$ CNT doped HAp and 0.5wt $\%$ CNT doped HAp

Table 1 Surface area and pore properties of pure HAp and graphite doped HAp sensor substrate

\begin{tabular}{|c|c|c|c|}
\hline \multirow{2}{*}{$\begin{array}{c}\text { Sensor Substrate } \\
\text { Pure HAp }\end{array}$} & $\begin{array}{c}\text { BET Surface Area } \\
\left(\mathrm{m}^{2} / \mathrm{g}\right)\end{array}$ & $\begin{array}{c}\text { Pore Volume } \\
\left(\mathrm{cm}^{3} / \mathrm{g}\right)\end{array}$ & $\begin{array}{c}\text { Pore Diameter } \\
(\mathrm{nm})\end{array}$ \\
\hline $0.2 \mathrm{wt} \%$ CNT doped HAp & 22.069 & 0.087 & 3.613 \\
\hline $0.5 \mathrm{wt} \%$ CNT doped HAp & 46.66 & 0.164 & 6.06 \\
\hline
\end{tabular}




\section{Sensing Properties:-}

Operating Temperature:-

The organic vapor sensing characteristic of both doped and undoped material is tested in the presence of $100 \mathrm{ppm}$ propanol. The variation in resistance is recorded at elevated temperature in order to calculate the sensitivity at that particular temperature. The plot in Figure 3 represents the relationship between the temperature and sensitivity in the presence of $100 \mathrm{ppm}$ propanol. The sensitivity is found to be maximum at $60^{\circ} \mathrm{C}$ for both doped and undoped material. Hence this temperature is considered as operating temperature for the detection of propanol by both the undoped and doped material which is kept constant for further investigation viz., response/recovery and uptake limit. Also, the study divulges that CNT doped material are more sensitive than undoped HAp while 0.2 wt $\%$ CNT doped HAp gives the best sensing performance. This may be because this particular weight concentration provides a huge specific surface area along with high active reaction sites that allow the detecting molecules to diffuse rapidly throughout the porous HAp surface and hollow nanotubes.

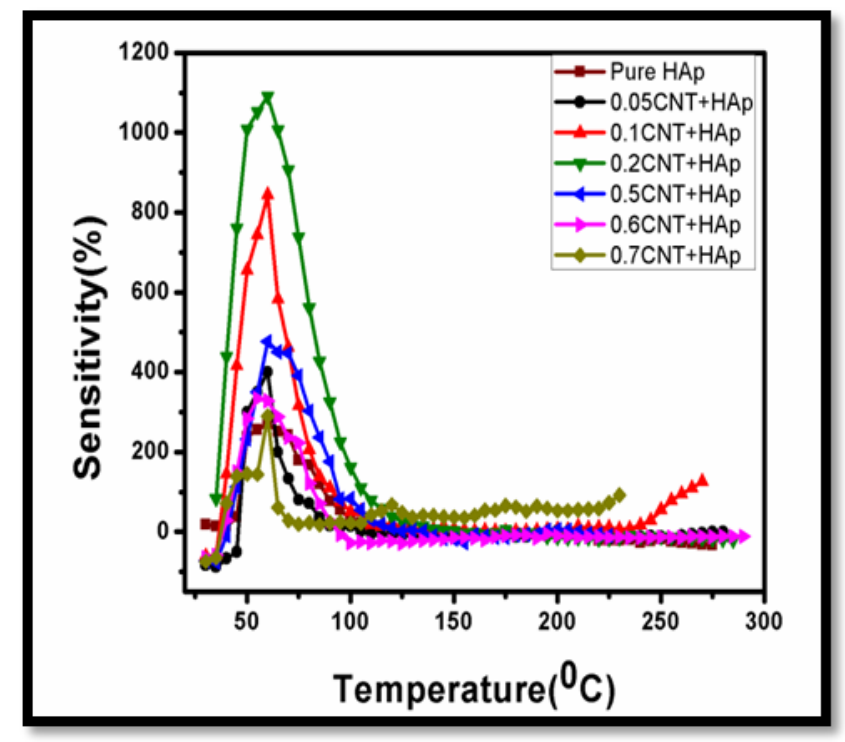

Figure 3 Exhibits relationship between sensitivity and temperature of undoped and doped HAp thick films in the presence of 100 ppm propanol.

\section{Response / Recovery time:-}

The response and recovery time of the sensor substrate is measured by holding the device at its operating temperature $60^{\circ} \mathrm{C}$. Figure 4 shows the dynamic response for the entire sample to propanol at their optimum temperature. As propanol vapors of volume $100 \mathrm{ppm}$ are injected, the sensor shows variation in resistance with time which reached a steady level within $90 \mathrm{sec}$. The recovery time is recorded by exposing the substrate to atmospheric air at its operating temperature. The slow recovery of the sensor is due to strong hydrogen bonding between the hydroxyl group and polar propanol molecules at the surface. Moreover, it is difficult for propanol vapors to come out easily from inside of the tubes (CNT).

\section{Maximum uptake capacity:-}

The effect of concentration of the propanol on the sensor substrate is also studied at the operating temperature. Figure 5 shows the variation in sensitivity of undoped and CNT doped HAp thick films for various concentrations of propanol vapors at their operating temperature of $60^{\circ} \mathrm{C}$. For CNT doped sensing substrate, the sensitivity increases rapidly with the concentration of propanol. Thus, the doped material exhibits high uptake capacity. Since the specific surface area is an important factor in order to study the maximum uptake limit of the sensor, the enhanced performance of the CNT doped material is attributed to its large specific area and porous hexagonal structure. 


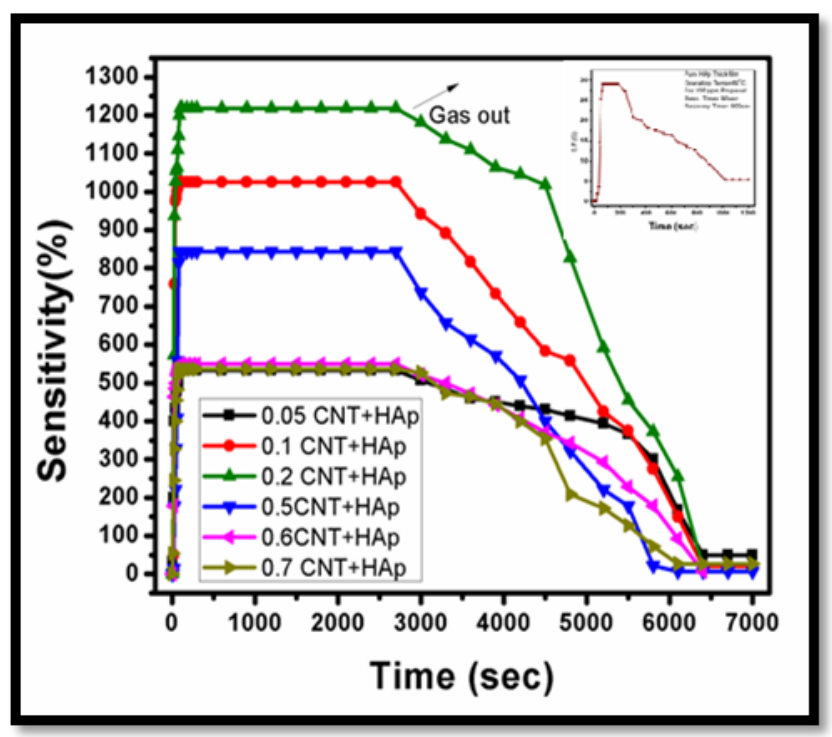

Figure 4 Response / Recovery time plot for screen printed HAp and CNT doped HAp thick films having different CNT concentration towards $100 \mathrm{ppm}$ propanol at their optimum temperature $\left(60^{\circ} \mathrm{C}\right)$.

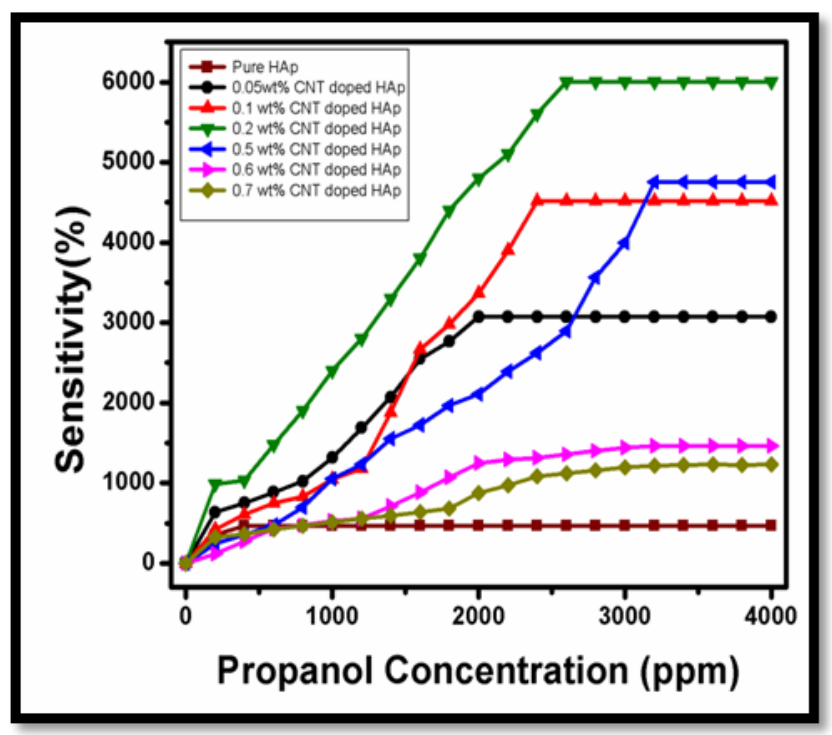

Figure 5 Sensitivity of undoped and doped HAp thick films for various concentrations of propanal vapors at their optimum temperature $\left(60^{\circ} \mathrm{C}\right)$.

\section{Conclusion:-}

Carbon nanotubes doped Hydroxyapatite sensing substrate is developed to monitor the presence of propanol vapours at low operating temperature. The influence of doping material for better propanol sensing property is studied. It is concluded that CNT doped HAp materials are more sensitive than pure HAp and the best sensing performance is shown by $0.2 \mathrm{wt} \%$ CNT doped HAp thick films for the detection of 100ppm propanol. The doped thick films show high sensitivity with large uptake capacity at $60^{\circ} \mathrm{C}$ in the presence of $100 \mathrm{ppm}$ propanol. Thus, $0.2 \mathrm{wt} \% \mathrm{CNT}$ doped HAp is a promising sensor material for the sensing of propanol at operating temperature of $60^{\circ} \mathrm{C}$. 


\section{References:-}

1. Ghasemi, and M. Molla, (2012). J. Chem. Tech. Research, 4(4): 1302-1308

2. S. Dasari, W. Taube, P. Agarwal, M. Rajput, and A. Kumar, and J. Akhtar, (2015). Sensors and transducer, 190(7): 24-30

3. Betsiou M, Sikalidis C, and Papageorgiou A,(2007), Bioautomation 8(1):138-145

4. Cawthray J., Creagth A., Haynes C., and Orvig C.,(2015). Inorganic Chem. 54(4): 1440-1445

5. Cummings L., Snyder M., and Brisack K., (2009). Methods Enzymol, 463:387-404

6. H. Ivankovic, S. Orlic, D. Kranzelic, and E. Tkalcec, (2010). Adva. Sci. Tech. 63:408.

7. H. Zhao, H. Zhou, J. Zhang, W. Zheng, and Y. Zheng, (2009).Biosens. Bioelec. 25: 463-468

8. J. Klinkaewnarong, S. Maensiri, and Chiang, (2010). Mai. J. Sci., 37(2):243

9. Joseph C. Obirai, Gray Hunter, and PrebirDutta, (2008). Sensors and actuators B, 134: 640-646

10. Li Huixia, Liu Yong, Tan Yanni, LuoLantan, Zhang Qing, Li Kun, and Tang Hanchunl, (2015). New. J. Chem. 39:3865-3874

11. M. Zahouily, W. Bahlaouan, B. Bahlaouan, and A. Rayadh, (2005), Arkivoc, 12: 150-161

12. P. Chavan, M. Bahir, R. Mene, M. Mahabole, and R. Khairnar, (2009). Mater. Sci. Eng. B. 168: 10-16

13. R. S. Khairnar, VanjaKokal, and S. R. Anjum, (2015). Int. J. Pure Appl. Res. Eng. Tech. 3(8): 379-86

14. R. S. Khairnar, K. A. Bogle, andN. Ingle, (2015). Int. J. Pure Appl. Res. Eng. Tech. 3(9): 135-42

15. R. U. Mene, M. P. Mahabole, and R. S. Khairnar, (2011).Radi. Phys. Chem. 80(6): 682-687

16. R. U. Mene, M. P. Mahabole, K. C. Mohite, and R. S. Khairnar, (2014). J. Alloys Comp., 584: 487-493

17. R. U. Mene, M. P. Mahabole, R. C. Aiyer, and R. S. Khairnar, (2010).Open Appl. Phys. J.3:10-16

18. R. U. Mene, M. P. Mahabole, Ramphal Sharma, and R. S. Khairnar, (2011). Vacuum 86(1): 66-71

19. Rajendra S. Khairnar, S. R. Anjum, Vanja Kokol, and M. P. Mahabole (2014). Int. J. Modern comm. tech. Res. 2 (4): 29-34

20. Rajendra S. Khairnar, Vanja Kokol, and S. R. Anjum, (2015). Int. J. Pure Appl. Res. Eng. Tech. 3(8): 37986

21. V.Narwade, M. Mahabole, K. Bogle and R. Khairnar, (2014). Int. J Engi. Sci. Innov. Tech.3(3): 324-329

22. Y. Du, Q. Xue, Z. Zhang, F. Xia, Z. Liu, and W. Xing, (2015). AIP Advan. 5: 027136 